Volume: 1 | Volumen 1 | Número 1 | Number 1 | pp. $63-70$ ISSN: 2634-355X (Print) | ISSN: 2634-3568 (Online) journals.tplondon.com/yeiya

First Submitted: 5 September 2020 Accepted: 24 November 2020

TRANSNATIONAL PRESS ${ }^{\circledR}$ DOI: https://doi.org/10.33182/y.v1i1.1314

\title{
Extractivismo, neoextractivismo y commoditties de ilusión desarrollista
}

\author{
Elizabeth Concha ${ }^{1}$
}

\section{Resumen}

2020 es la expresión del cúmulo de consecuencias provocadas por un capitalismo rapaz. La degradación del medio ambiente por la explotación de los recursos naturales crece en forma exponencial y a un ritmo nunca visto en otra época de la historia económica. Por lo que, dar a conocer las alternativas al desarrollo económico y compartir conocimiento de entrelazamiento de estas con la sociedad, son necesarios en las discusiones de cualquier lugar, desde centros de investigación hasta una pequeña comunidad o localidad, qué es el extractivismo y el neoextractivismo como modo de relación social de crecimiento económico a base de la explotación y destrucción de los recursos naturales, remarcar que a pesar de que pueden ser medio de crecimiento económico ciertos productos como los minerales, su explotación se ve inmersa en una ilusión desarrollista, dominada por el capital financiarizado, y por último sus consecuencias y manifestaciones de los que reconocen la importancia de la tierra, agua, aire y que nos anuncian de que sin la recuperación de esa conexión ancestral de esos elementos, no habrá desarrollo económico.

Palabras clave: extractivismo; neoextractivismo; ETFs; ETP; commodities

\section{Abstract \\ Extractivism, neo-extractivism and developmentalist illusion commodities}

2020 is the expression of the cumulus of consequences caused by a rapacious capitalism. The degradation of the environment due to the exploitation of natural resources is growing exponentially and at a rate never seen in any other time in economic history. So, make known the alternatives to economic development and sharing knowledge of their intertwining with society are necessary in discussions anywhere, from research centers to a small community or locality, what is extractivism and neo-extractivism as a form of social relationship of economic growth based on the exploitation and destruction of natural resources, emphasize that although certain products such as minerals can be a means of economic growth, their exploitation is immersed in a developmental illusion, dominated by financialized capital, and finally its consequences and manifestations of those who recognize the importance of the land, water, air and who announce to us that without the recovery of that ancestral connection of these elements, there will be no economic development.

Keywords: extractivismo; neo-extractivism; ETFs; ETP; commoditie

\section{Introducción}

2020 es la expresión del cúmulo de consecuencias provocadas por un capitalismo rapaz. La degradación del medio ambiente por la explotación de los recursos naturales crece en forma exponencial y a un ritmo nunca visto en otra época de la historia económica. La manifestación de una crisis multidimensional económica-política-social-financiera-sanitaria-ambiental, da como resultado una situación de alerta, solo por señalar un ejemplo, de la crisis sanitaria

${ }^{1}$ Universidad Autónoma Metropolitana. Ciudad de México, México. Correo electrónico: egcr@xanum.uam.mx 
mundial actual causada por el virus SARS-COv-2 (Covid-19), ha cobrado más de 1 millón 560 mil muertes y 68 millones de infectados (cifras a 9 de diciembre, CNA, 2020). Una manifestación de la reacción de la capacidad del planeta tierra de saneamiento. Por lo que, dar a conocer las alternativas al desarrollo económico y compartir conocimiento de entrelazamiento de estas con la sociedad, son necesarios en las discusiones de cualquier lugar, desde centros de investigación hasta una pequeña comunidad o localidad, qué es el extractivismo y el neoextractivismo como modo de relación social de crecimiento económico a base de la explotación y destrucción de los recursos naturales, remarcar que a pesar de que pueden ser medio de crecimiento económico ciertos productos como los minerales, su explotación se ve inmersa en una ilusión desarrollista, dominada por el capital financiarizado, y por último sus consecuencias y manifestaciones de los que reconocen la importancia de la tierra, agua, aire y que nos anuncian de que sin la recuperación de esa conexión ancestral de esos elementos, no habrá desarrollo económico.

\section{Extractivismo y neoextractivismo}

La historia económica pone al extractivismo como un componente del capitalismo (acumulación original-acumulación financiera), con rasgos que atraviesan los sucesivos ciclos económicos, dependientes de las necesidades del mercado mundial y la consolidación de Estados Nacionales, más cuando una de sus fuerzas era en base en la producción de bienes provenientes del petróleo y productos mineros.

En las aportaciones teóricas y de análisis de Alberto Acosta encontramos que el extractivismo es “... una modalidad de acumulación que comenzó a fraguarse masivamente hace 500 años”, así mismo, Horacio Machado concreta al extractivismo como "un rasgo estructural del capitalismo como economia-mundo" (citado por Svampa, 2015:15). Para Gudynas (2009, 2011, 2014), el extrativismo es un tipo de extracción de recursos naturales, en gran volumen o alta intensidad, orientados esencialmente a ser exportados como materias primas sin procesar, o con un procesamiento mínimo, entonces lo refiere a la extracción de todos los bienes de los llamados recursos renovables y no renovables (hidrocarburos, monocultivo, pesquerías, etc.), y no solo a la minería y agricultura (Gudynas, Acosta, 2011). Su manifestación en economías como las latinoamericanas es bajo las llamadas "economías de enclave", es decir, como si fueran una "isla", sin relación y vinculación con el resto de la economía nacional. Esto se debe a que una parte importante de sus insumos y tecnologías son importadas, una proporción significativa de su personal técnico es extranjero, y sin relación a las cadenas industriales nacionales. Esto hace que las contribuciones a las economías locales o regionales sean muy limitadas, y el grueso de sus ganancias quedan en sus casas matrices. El extractivismo no debe confundirse con una economía primario-exportadora, más bien una economía primario-exportadora puede tomar la modalidad de enclaves extractivistas, un modo de apropiación antes de un modo de producción, un modo de producción que refiere a un crecimiento exponencial de la explotación de los recursos naturales, no procesados con el uso intensivo de agua, energía y otros recursos, conocidos en la actualidad como extractivismismo de tercera y cuarta generación (Svampa, 2019:15).

Finalmente, Svampa Maristella (2019:16) señala que, "la dimensión bistórico-estructural del extractivismo está vinculada a la invención de Europa y la expansión del capital. Asociada a la conquista y el genocidio", "Desde tiempos de la conquista, los territorios latinoamericanos ban sido coto de destrucción y de saqueo. Rica en recursos naturales, la región se fue reconfigurando una y otra vez al calor de los sucesivos ciclos 
económicos, impuestos por la lógica del capital, a través de la expansión de las fronteras de las mercancías; una reconfiguración que a nivel local conllevó grandes contrastes entre rentabilidad extraordinaria y extrema pobreza, así como una gran pérdida de vidas humanas y de degradación de territorios, convertidos en áreas de sacrificio", "a comienzos del siglo XXI, el extractivismo se encargó de nuevas dimensiones", el neoextractivismo.

Por lo que, a partir de 2008 los llamados países progresistas motivaron una reflexión conceptual sobre la diferenciación de lo que se conoce como extractivismo clásico y el neoextractivismo o nuevo extractivismo progresista. La diferencia esta en la función del Estado, en el primero tiene un papel secundario, su presencia es en apoyo de las inversiones principalmente extranjeras y las exportaciones con bajos niveles de tributación, dejando al mercado el funcionamiento de la economía, aquí las grandes empresas son las que sobresalen, ejemplo de países son Colombia y México. En el segundo, el Estado participa con empresas paraestatales o mixtas, el nivel de las regalías y la imposición es más elevada, y hay mayores controles a la explotación, este extractivismo desplegado por los gobiernos progresistas, lo aplicaron y legitimaron de otra manera dimensionándolo a un nuevo concepto, el neoextractivismo, justificado políticamente ante la opinión pública como necesario para el progreso, y en particular para captar mayores proporciones de riqueza, la que será devuelta a la sociedad mediante programas sociales, ejemplo de países son Bolivia, Ecuador y Venezuela. En el neoextractivismo, si bien el Estado juega un papel más activo, y logra una mayor legitimación por medio de la redistribución de algunos de los excedentes generados, por ese extractivismo, de todos modos, se repite los impactos sociales y ambiéntales degenerativos (Gudynas, 2009: 188). Para Lander Edgardo (2014), como modelo de desarrollo, no hay diferencias sustantivas entre uno y el otro, sino una continuidad o profundización de la primera del patrón productivo primario exportador y subutilización de los recursos naturales.

Sin embargo, Svampa Maristella (2019:21), dice que el neoextractivismo no debe ser solo una visión plana, sino un concepto complejo "una ventana privilegiada para leer en sus complejidades y diferentes niveles las múltiples crisis que recorren las sociedades contemporáneas", lo define como "un modelo de desarrollo basado en la sobreexplotación de bienes naturales, cada vez más escasos, en gran parte no renovables, asi como la expansión de las fronteras de explotación hacia territorios antes considerados como improductivos desde el punto de vista del capital". El neoextractivismo contemporáneo se caracteriza por; a) exportación de bienes primarios a gran escala; b) incluye a otras actividades, megaminería, petroleras, energía, hidroeléctricas, infraestructura, monocultivos, sobreexplotación pesquera o monocultivos forestales, etc; c) Por ser un modelo sociopolíticoterritorial el conflicto de intereses alcanzan la escala nacional, regional y local; d) gigantescas inversiones en megaproyectos de grandes empresas mineras, petroleras, etc.; e) ocupación intensiva del territorio y el acaparamiento de tierras y con ello una redefinición de las disputas por la tierra, una relación abismal de los interés de los agentes involucrados sociedad-gobiernoempresa.

Colocar a los recursos naturales y la producción de commodities en el eje del discurso oficial e internacional de un progreso económico y social, da como resultado un crecimiento exponencial del Producto Interno Mundial (1960, 1.4 miles de millones de dólares, mmdd; 1980, 11.2 mmdd; 2000, 33.6 mmdd; y 2019, 86.6 mmdd, datos del Banco Mundial), a expensas de la destrucción de la naturaleza y una expresión del capitalismo actual, la financiarización. Así como propuestas de tomar la explotación de ciertos productos como vías para el logro de un crecimiento y desarrollo económico. 


\section{Commodities en la ilusión desarrollista, oro y plata}

$\mathrm{Al}$ inicio del nuevo milenio "llegaron sin anticipación el auge de los commodities, por fuerzas inercialesy antrópicas", donde muchas economías de América Latina y México, ante altos precios de bienes primarios tuvieron el efecto de provocar un proceso de "re-primarización", lo que provocó un aumento de las actividades agropecuarias, mineras y petroleras, principalmente; un aumento de las actividades de menor procesamiento industrial de los productos primarios, aumento de la infraestructura para los enclaves primarios exportadores; aumento masivo de stocks de bienes primarios no perecederos y una especulación financiera de los commodities (Cypher, 2016) .

En el caso de la minería su proceso de producción ya no es solo subterránea, sino se le suman los de cielo abierto y marino, para lograr un alcance de explotación de minerales en cantidades exponenciales. Con respecto a los metales preciosos oro y plata, con datos de la U.S Department of the Interior y Geological Survey de Estados Unidos, se puede constatar que lo producido en solo 13 años supera al doble de lo producido en 4 siglos. En la producción de oro a nivel mundial, en el periodo de 1493-1910 se produjo 19 miles de toneladas (mdt) de oro, y en el periodo 2006-2019 se produjo $39.4 \mathrm{mdt}$. Asimismo, pasa con la plata, $302.1 \mathrm{mdt}$ y $344.3 \mathrm{mdt}$, respectivamente (Concha, 2017).

Este auge expansivo de la explotación de los recursos naturales como los minerales preciosos oro y plata, se presentan bajo una ideología financiarizada, es decir, se les nombra "inversiones refugio", activos financieros menos expuestos a las fluctuaciones de un ciclo económico y por tanto un refugio del capital en época de crisis, mostrando una mayor participación en los años posteriores de la crisis financiera de 2008, en las demandas mundiales de oro los Exchange Traded Funds (ETFs) ${ }^{2}$, y de la plata de los Exchange Traded Products (ETP).

En el periodo de 2003 a 2019, los ETFs de oro acumularon aproximadamente 2.9 mil toneladas de oro, por un valor de 143 mil millones de dólares. El crecimiento es particularmente por la incorporación de nuevos inversores en oro en todo el mundo, principalmente de Europa. A este peculiar elemento se suma uno más, rendimientos positivos, de largo plazo, y superiores al de las acciones y bonos, de 10.5 por ciento promedio anual desde 1971 (World Gold Council, 2020: 2), y en el periodo de confinamiento por el Covid19, el oro es el commoditie más rentable, como se puede ver en la gráfica 1.

A pesar de que la demanda de oro se concentra en la joyería, inversión en barras y monedas, el uso industrial en electrónicos, con un notable incremento en los últimos años; uso dental y médico, en 2020 la inversión mundial del oro presentó un fuerte crecimiento, a pesar de la desaceleración económica y las restricciones provocadas por el Covid-19. Los ETFs respaldados en oro, aunque presentaron un ritmo más lento, el primer semestre del 2020, la inversión en este activo financiero tuvo un flujo record de 1,003.3 toneladas, como se muestra en la gráfica 2.

\footnotetext{
${ }^{2}$ Los contratos a futuro también se denominan papel-oro o ETF y son certificados que garantizan la posesión de cierta cantidad de oro, monedas o lingotes, que el vendedor se compromete a entregar físicamente si el comprador la exige. Este tipo de mercado se clasifica dentro de los no-regulados y está bajo el sistema OTC (Over-the-Counter).
} 
Gráfica 1. Rendimiento internual de los principales activos mundiales a junio de 2020 (\%).

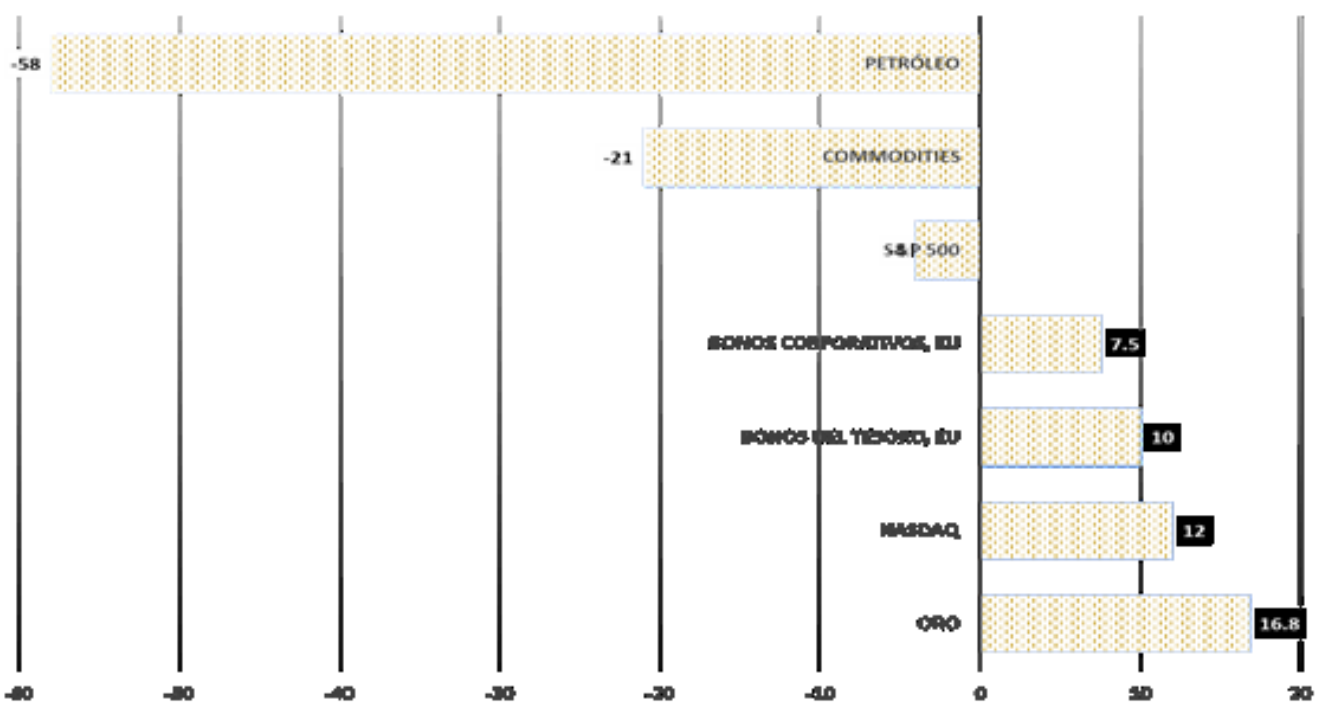

Fuente: Elaboración propia con información de World Gold Council (2020), Gold mind-year outlook 2020. Recovery paths and impact on performance. Chart 1, Disponible en www.gold.org

Gráfica 2. Demanda de toneladas de oro por EFTs y productos similares.

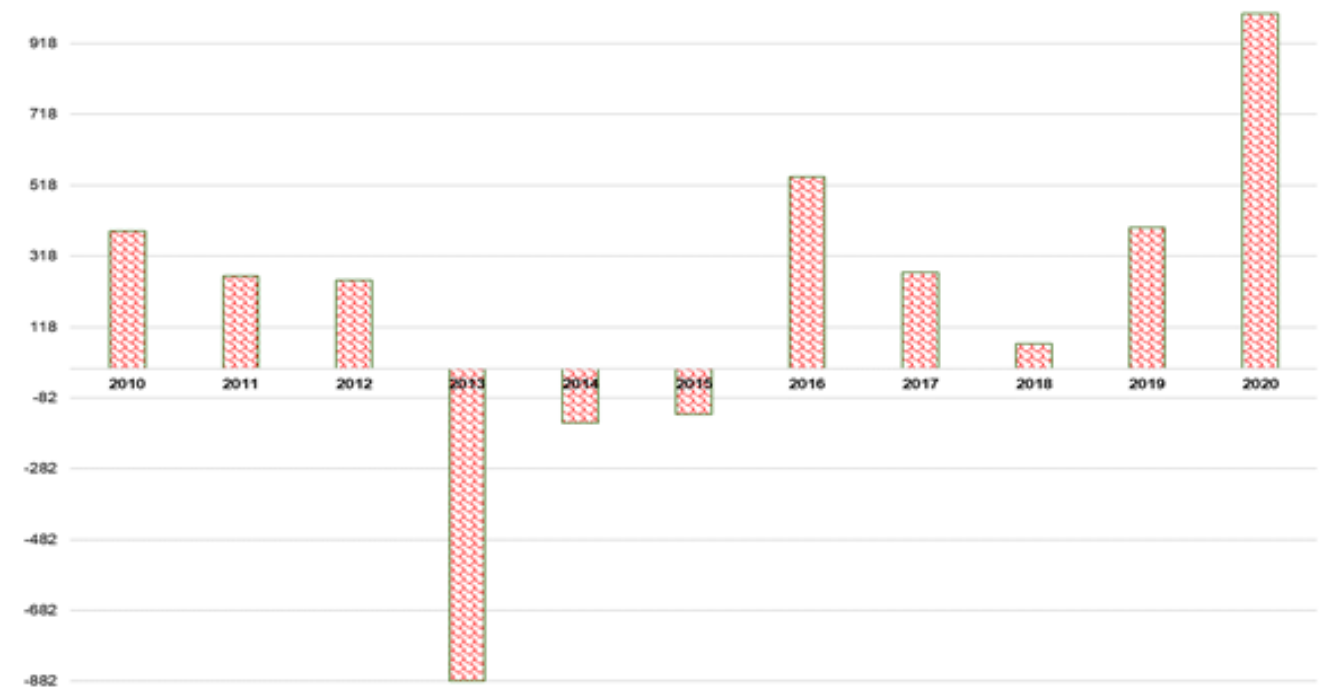

Fuente: Elaboración propia con información de World Gold Council, “Gold Demand Trends Q3 2020”, Table Gold Demand, www.gold.org, datos a septiembre de 2020.

En el caso de la plata el mayor uso es el industrial en la producción de eléctricos y electrónicos, soldaduras y fotografía; le sigue la joyería y artículos de joyería; inversión en monedas y barras; y finalmente ETFs y ETPs. Los ETP (Exchange Traded Products) son un tipo de instrumentos financiero recién propuesto (2006), cotizados en mercados regulados, y reflejan valores subyacentes, de un índice u otros instrumentos financieros. Los ETP son valores que cotizan en bolsa y ofrecen exposición a los precios de plata mediante la tenencia de posiciones físicas 
de futuros o OTC, no son ETF, ya que no cumplen con el requisito de la diversificación. Los ETP con respaldo físico están respaldados por cantidades asignadas almacenadas en una bóveda reconocida. Uno de sus rasgos a partir de su lanzamiento es la participación de inversionistas minoristas, que aprovechan las caídas en los precios para comprar y sus participaciones tienden a ser resistentes. A pesar de que ha tenido altas y bajas las tenencias de plata en ETP han alcanzado máximos históricos en términos de volumen, en la gráfica 3, muestra como a partir del 2020 los ETP pasan de 700 millones de onzas (Moz) a finales de 2019 a $925 \mathrm{Moz}$ (28.77 toneladas) a septiembre de 2020, aproximadamente 13 miles de millones de dólares (\$bn) a 30 miles de millones de dólares, respectivamente, impulsados por los fondos estadounidenses, y los mercados lideres de Europa (The Silver Institute, 2020 y Newman 2000).

Gráfica 3. Tenencias de ETP.

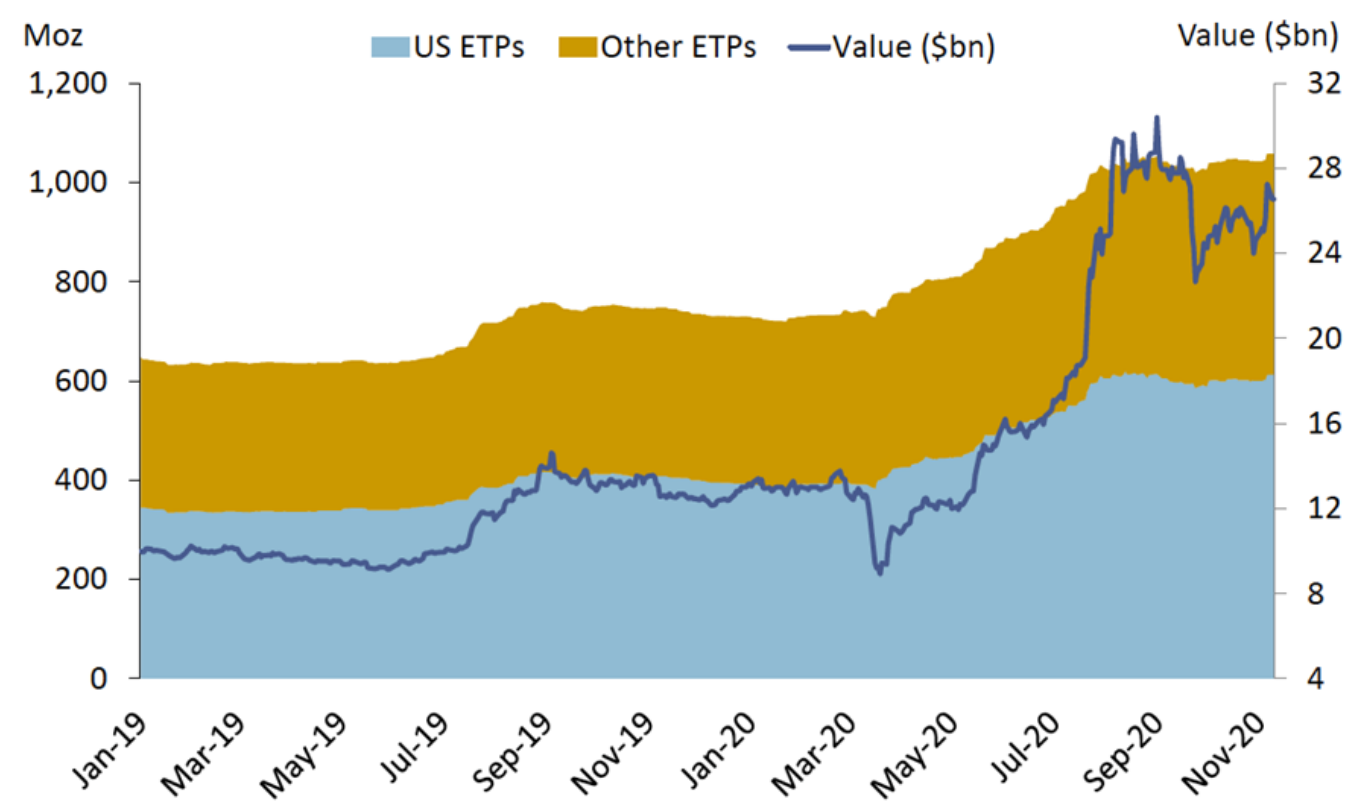

Fuente: Newman P. y Webb A (2020), Interim Silver Market Review 2020", November 17th, pág. 13, Disponible en www. silverinstitute.org/.

\section{Consecuencias de la ilusión desarrollista}

Entonces pensar en un nuevo neoextractivismo como medio para un desarrollo económico, resulta una imagen recóndita, ya que sus resultados son la marginación social, pobreza, destrucción del tejido social ante un vacío en la participación social. Estados permisivos en la violación de la legitimidad de los marcos legales respecto a los recursos naturales y derechos humanos. Una configuración del trabajador (a) a corto plazo. Grandes empresas transcendentes en lo cultural, político y jurídico, para conformar un poder corporativo que nutren y renuevan con el proceso actual de acumulación financiera (con un conjunto de estrategias), se presentan como grandes desarrollos o planes de megaproyectos de sus matrices instalados en sus subsidiarias, convertidos en un instrumento corporativo de arrebato de los espacios territoriales, en economías en desarrollo (Concha, 2017 y Fernández, 2019). 
Además, el neoextractivismo como una expresión central de la etapa actual del capitalismo basada en la sobreexplotación de los recursos naturales, para la producción de bienes a nivel mundial; la presencia de China (en la explotación de recursos minerales como principal productor, por ejemplo en recursos mineros: antimonio, carbón, barita, hierro, etc.); y los cambios tecnológicos, colocan la mirada de muchos megaproyectos mineros, hidroeléctricos, petroleros, y de agricultura moderna, de grandes empresas en los recursos naturales del sur global y América Latina. Provocando los movimientos socioambientales de muchos países del mundo y en particular en América Latina, en la lucha ancestral por la tierra, condiciones y calidad de vida.

En el caso de la minería, el Tribunal Permanente de los Pueblos ha alertado que las minas son la mayor causa de tensiones en América Latina, al generar más de 200 conflictos sociales en la región (solo Perú reporta, 194 conflictos sociales, en 2018). En el documento "Conflictos mineros en América Latina: extracción, saqueo y agresión. Estado de situación en 2018”, describen los casos Argentina, Bolivia, Brasil, Chile, Ecuador, El Salvador, México, Nicaragua, Panamá y Perú. Las luchas, las marchas, los escritos, las manifestaciones, etc. son por derrames de sustancias tóxicas, violación a las leyes, puesta en marcha de proyectos de exploración y explotación sin estudios de impactos ambientales, uso y contaminación de ojos de agua, minería ilegal, rompimiento de represas, etc. Las grandes empresas involucradas por mencionar algunas son Barrick Gold, Samarco, Vale, BHP Bolliton, Anglo American, Southerm Copper Gold, Junefield Resources, Gold Corp (Newmont Gold Corp.), Grupo México, etc. Empresas de capitales australianos, canadienses, chinos, estadounidenses y mexicanos, principalmente (OCMAL, 2019).

\section{Comentarios finales}

Reconocer la importancia ancestral de los elementos de la tierra es una tarea que pequeñas localidades hacen día con día y deberán ser empujadas a construirse como una fuerza de comunidades aisladas hacia lo nacional e internacional, sin ello solo habrá una tendencia a la destrucción y aniquilación de la vida humana. Las nuevas propuestas del extractivismo, neoextractivismo, el post-crecimiento y el buen vivir, deberán centrarse en una acción de las partes involucradas para hacer un entrelazamiento de información-pensamiento-decisiónplaneación-acción de la sociedad con los gobiernos y las grandes empresas, para pensar en una configuración de capitalismo actual para la sobrevivencia humana, su fin no se visualiza al menos en un largo plazo y crisis sanitarias como el Covid-19 solo agudiza más la situación.

\section{Referencias}

Acosta, A. (2011). Extrativismo y neoextrativismo: Dos caras de la misma maldición. En Grupo Permanente de Trabajo sobre Alternativas al Desarrollo, Más allá del desarrollo. Recuperado de http://www. rosalux.org.ec

Acosta, A. (Ed.). (2014). Desarrollo, Postcrecimiento y buen vivir. Debates e interrogantes. Recuperado de htpp://www.rosalux.org.ec

Banco Mundial (2020), Data, GDP current dollars. Recuperado de http://www.worldbank.org

Channel News Asia (CNA). (2020). Mapa de nivel de coronavirus. Recuperado de https://infographics. channelnewsasia.com/covid-19/map.html

Concha, E. (2017). Minería mundial contemporánea o financiarizada. OLAFINANCIERA, 10 (27): MayoAgosto 2017, México, UNAM. 
Cypher, J. (2016). La economía política de América Latina "re-primarizada durante y después del auge de commodities: 2002-2013. En J. Déniz, J. y E. Correa (Ed.), Estrategias Primario-Exportadoras en un Mundo Global. México-Zacatecas: Universidad Autónoma de Zacatecas y Miguel Ángel Porrúa.

Fernández, G. (2019). El poder corporativo al asalto de los territorios claves para la resistencia popular a los megaproyectos. En Territorios en conflicto claves para la construcción de alternativas de vida. Recuperado de https://www.gernikagogoratuz.org/portfolio-item/territorios-en-conflicto-claves-parala-construccion-de-alternativas-de-vida/

Gudynas, E. (2009). Diez tesis urgentes, sobre el nuevo extrativismo. Contexto y demandas bajo el progreso sudamericano actual. Recuperado de http://www.gudynas.com/publicaciones/GudynasNuevo Extractivismo10Tesis09x2.pdf

Gudynas E. (2011). Debates sobre el desarrollo y sus alternativas en América Latina: Una breve guía heterodoxa. En Grupo Permanente de Trabajo sobre Alternativas al Desarrollo, Más allá del desarrollo. Recuperado de http://www.rosalux.org.ec

Gudynas, E. (2013). Postextractivismo y alternativas al desarrollo desde la sociedad civil. En Grupo Permanente de Trabajo sobre Alternativas del Desarrollo, Alternativas al capitalismo del siglo XXI. Recuperado de http://www.rosalux.org

Gudynas, E. (2011). El nuevo extractivismo progresista en América del Sur. Tesis sobre un viejo problema bajo nuevas expresiones. En Colonialismos del siglo XXI. Negocios extractivos y defensa del territorio en América Latina. Varios autores. Icaria Editorial, España.

Lander, E. (2014). El neoextrativismo como modelo de desarrollo en América Latina y sus contradicciones. Recuperado de https://mx.boell.org/sites/default/files/edgardolander.pdf

Newman, P. y Webb, A. (2020). Interim Silver Market Review 2020. The Silver Institute, November17th. Recuperado de https://www.silverinstitute.org

OCMAL (2019). Conflictos mineros en América Latina: Extracción, saqueo y agresión. Estado de situación en 2018. Recuperado de www.ocmal.org

Svampa, M. (2019), Las fronteras del neoextractivismo en América Latina. Conflictos socioambientales, giro ecoterritorial y nuevas dependencias, Calas. Recuperado de http://calas.lat/sites/default/files/ svampa_neoextractivismo.pdf

The Silver Institute (2020). World Silver Survey 2020. Recuperado de https://www.silverinstitute.org

World Gold Council (2020). Gold Demand Trends Q3 2020. Recuperado de http://www.gold.com

World Gold Council (2020). Gold mind-year outlook 2020. Recovery paths and impact on performance.

Recuperado de http://www.gold.org 